\title{
TEORIA DOS SISTEMAS SOCIAIS E ANÁLISE DE REDES: UMA NOVA PERSPECTIVA PARA COMPREENDER A CONSTITUIÇÃO BRASILEIRA
}

THEORY OF SOCIAL SYSTEMS AND NETWORK ANALYSIS: A NEW PERSPECTIVE TO UNDERSTAND THE BRAZILIAN CONSTITUTION

\author{
TEORÍA DE LOS SISTEMAS SOCIALES Y ANÁLISIS DE REDES: UNA NUEVA \\ PERSPECTIVA PARA COMPRENDER LA CONSTITUCIÓN BRASILEÑA
}

Licença CC BY:

Artigo distribuído sob

os termos Creative

Commons, permite

uso e distribuição

irrestrita em qualquer

meio desde que o

autor credite a fonte

original.

\section{Rafael Silveira e Silva ${ }^{1}$}

Pedro Fernando Nery²

João Trindade Cavalcante filho ${ }^{3}$

\section{(c) (i)}

Resumo: Nesta pesquisa parte-se do pressuposto de que a norma constitucional tem o condão de revelar, sob uma forma organicamente alternativa, como seus dispositivos "dialogam" uns com os outros, formando subsistemas à luz das teorias de Luhmann e Teubner. Com o auxílio da metodologia de análise de redes, propõe-se um modelo interpretativo, tomando-se por base as remissões internas existentes na Constituição, revelando-a sob outro prisma. O objetivo é identificar a rede de relacionamento e a existência de subsistemas no texto constitucional formados de maneira imperceptível se apenas levarmos em conta a mera organização nos diversos títulos, subtítulos e capítulos. Como resultado, identificou-se uma rede que abrangeu ligações entre mais de cem artigos da Constituição e a existência de subsistemas cujos códigos ou padrões comunicativos ressaltam a defesa de direitos individuais a partir da limitação do poder do Estado.

1 Doutor e Mestre em Ciência Política pela Universidade de Brasília; Professor do Programa de Pós-Graduação em Direito do Instituto Brasiliense de Direito Público (IDP), do Instituto Legislativo Brasileiro (ILB) e Pesquisador Associado do Instituto de Ciência Política da Universidade de Brasília. Coordenador do Núcleo de Estudos e Pesquisas da Consultoria Legislativa do Senado Federal. E-mail: rafael.silva@idp.edu.br.

2 Doutor e Mestre em Economia pela Universidade de Brasília; Professor do Programa de Pós-Graduação em Administração Pública do Instituto Brasiliense de Direito Público (IDP); Agraciado com o Edgardo Buscaglia Award on Empirical Research in Law and Economics (2013), conferido pela Associação Latino Americana e Ibérica de Direito e Economia (ALACDE). E-mail: pedrofernandonery@hotmail.com.

3 Doutorando em Direito Constitucional pela Universidade de São Paulo (USP). Mestre em Constituição e Sociedade pelo Instituto Brasiliense de Direito Público (IDP). Professor de Direito Constitucional do Instituto Brasiliense de Direito Público (IDP).E-mail: jtcfilho@senado.gov.br. 
Palavras-chave: Análise de redes; Constituição; Sistemas; Subsistemas.

Abstract: This research starts with the premise that the constitutional norm has the power to reveal, in an organically alternative way, how its devices "dialogue" with each other, forming subsystems in light of Luhmann and Teubner's theories. Using network analysis methodology, an interpretive model is proposed, based on the internal references that exist in the Constitution, revealing it in another light. The objective is to identify the relationship network and the existence of subsystems in the constitutional text, formed imperceptibly if we only take into account the mere organization in the various titles, subtitles and chapters. As a result, a network was identified that covered links between more than a hundred articles of the Constitution, and the existence of subsystems whose codes or communicative standards emphasize the defense of individual rights based on the limitation of state power.

Keywords: Network analysis; Constitution; Systems; Subsystems.

Resumen: En esta investigación se parte del presupuesto de que la norma constitucional tiene el don de revelar, bajo una forma orgánicamente alternativa, como sus dispositivos "dialogan" unos con los otros, formando subsistemas delante de las teorías de Luhmann y Teubner. Con el auxilio de la metodología de análisis de redes, se propone un modelo interpretativo, tomando como base las remisiones internas existentes en la Constitución, revelándola bajo otro prisma. El objetivo es identificar la red de relaciones y la existencia de subsistemas en el texto constitucional formados de manera imperceptible si apenas llevamos en cuenta la mera organización en los diversos títulos, subtítulos y capítulos. Como resultado, se identificó una red que cubría vínculos entre más de cien artículos de la Constitución y la existencia de subsistemas cuyos códigos o patrones comunicativos destacan la defensa de derechos individuales a partir de la limitación del poder del Estado.

Palabras clave: Análisis de redes; Constitución; Sistemas; Subsistemas.

\section{INTRODUÇÃO}

Atualmente, as constituições estão situadas no ápice dos ordenamentos jurídicos, uma vez que prescrevem princípios e procedimentos que conferem validade às leis e a todo o conjunto normativo que representa a ação e a intermediação estatal. O movimento de valorização constitucional não apenas diz respeito a esta hierarquia adquirida por um longo processo de valorização e organização social, mas também ao destaque de posições temáticas historicamente e socialmente relevantes, desde assuntos de natureza essencialmente constitucional, mas, também, e fugindo ao sentido formal, de aspectos da realidade social subjacente a estas normas.

Nossa Constituição possui um conteúdo rico e complexo. Seus termos passam pelo estabelecimento de princípios democráticos, republicanos e pluralistas, pela garantia de liberdades e de direitos individuais e coletivos e pela limitação do poder do Estado; por outro lado, também evidencia um caráter dirigente, por meio de dispositivos programáticas e diretrizes a serem cumpridas pelo Estado, especialmente com um amplo rol de direitos sociais. Sem desconsiderar a lógica e a organização do texto constitucional nos diversos títulos, capítulos, seções e subseções, nem 
sempre é possível estabelecer uma compreensão e, principalmente, uma nítida conexão entre suas diversas partes, a não ser quando os temas e assuntos são expressamente vinculados. Nesse sentido, entendemos, que a natureza e a composição dos temas e assuntos tratados na Constituição de 1988 podem revelar relações não diretamente perceptíveis, demonstrando possibilidades de compreensão que podem ir além dos métodos tradicionais de interpretação.

Propomos, então, fazer um exercício de visualização da Constituição como uma rede de relações, tomando por base a análise de redes aplicada às Ciências Sociais. De modo geral, tratase de uma abordagem eminentemente metodológica que evidencia os processos interativos entre indivíduos a partir de suas relações, que é considerado por muitos como um conceito central na análise dos processos estruturadores da sociedade, que fornece elementos para a compreensão de fenômenos sociais.

Desse modo, partimos do pressuposto de que a norma constitucional tem o condão de nos revelar de uma forma organicamente alternativa, como seus dispositivos "dialogam" uns com os outros. Ademais, tais diálogos ou relações podem ser reveladores da existência de subsistemas no texto constitucional, reunidos de forma imperceptível se apenas levarmos em conta a mera organização nos diversos títulos, subtítulos e capítulos. Esses subsistemas podem apresentar códigos próprios, à luz do que afirmam teóricos como Niklas Luhman e Gunther Teubner, e podem imprimir sentido e conteúdo aos agentes sociais. Assim, não apenas as relações entre esses agentes seriam propulsoras da criação de princípios e direitos constitucionais, mas também o próprio subsistema poderia ser indutor de realidades orientadoras das ações dos agentes.

Ademais, a descoberta desses elementos de interação poderá fornecer relações internas que são capazes de mostrar a Constituição em matizes, diferentes.

O objetivo deste trabalho é propor um modelo exploratório e interpretativo para encontrar possíveis subsistemas no texto constitucional com base nas referências internas de seu próprio conteúdo. Nossa intenção é identificar as características estruturais da rede de relacionamento capaz de identificar esses subsistemas, especialmente com a ajuda de ferramentas computacionais e de exploração visual, com interesse em realizar uma primeira interpretação de padrões compartilhados ao longo dos diversos dispositivos constitucionais. Isso permitirá a visualização do texto da Constituição como um mapa, além de detectar quais artigos são os que mais se conectam com outros artigos, bem como aqueles que são mais periféricos. $\mathrm{E}$, o mais importante, observar os diferentes subsistemas na Carta Magna e seus possíveis padrões comunicativos. 


\section{SISTEMAS, SUBSISTEMAS, COMUNICAÇÃO E CÓDIGOS: UMA BREVE VISÃO DAS TEORIAS DE LUHMANN E TEUBNER}

A teoria de Luhmann se fundamenta nos conceitos de "sistemas sociais" e na "comunicação".

O conceito de sistemas, desenvolvido a partir da Teoria Geral dos Sistemas do biólogo Karl Ludwig von Bertalanffy ${ }^{4}$ é definido por Alvarez ${ }^{5}$ como um conjunto de elementos interdependentes que interagem com objetivos comuns formando um todo, e onde cada um dos elementos componentes comporta-se, por sua vez, também como um sistema. O resultado dessa interação seria maior do que aquele alcançado por cada uma as unidades se funcionassem independentemente. Segundo Luhmann, os sistemas são diferenças operacionais capazes de produzir sentido; são formas fractais.

Luhmann defende que a sociedade é um macrossistema de grande complexidade com diversos subsistemas ou sistemas sociais que geram condições para si próprios e para os outros ao seu redor ${ }^{6}$. Significa dizer que a definição de sociedade não pode ser mais compreendida de um único ponto de vista dominante, mas interpretada à luz de sua ${ }^{7}$ diferenciação. Os sistemas sociais formadores da sociedade formam um conjunto dotado cada qual de uma autorreferência e que se modifica a partir de suas próprias bases internas. Luhmann indica que os sistemas sociais, então, são autopoiéticos ${ }^{8}$ porque se autorreproduzem ${ }^{9}$ enquanto unidade sistêmica.

Para que o sistema se renove internamente, um fator determinante é a comunicação, por meio da qual diferentes subsistemas sociais se diferenciam e se influenciam. Na essência, Luhmann entende os sistemas sociais como sistemas comunicativos, argumentando que não seria o ser humano quem comunica, mas o sistema social. Para Bachur, a "sociedade não é então composta por indivíduos, tradicionalmente tomados como unidades elementares do todo social, mas por circuitos comunicativos funcionalmente diferenciados, encarregados de desempenhar uma função social: a tomada de decisões coletivamente vinculantes pela política, o regramento da escassez pela economia, a estabilização congruente de expectativas pelo direito etc."10

$4 \quad$ Trata-se de uma teoria inicialmente apresentada em 1950, de caráter interdiciplinar, aplicada em diversas áreas do conhecimento humano. A teoria dos sistemas de Bertalanffy, baseado em seu conhecimento biológico, buscou compreender além o funcionamento isolado dos sistemas menores existentes em um ser vivo(sistema circulatório, respiratório e outros), e a importância do inter-relacionamento desses sistemas entre si e com o próprio sistema maior, o ser vivo. A percepção de Bertalanffy avançou além das fronteiras biológicas, indicando uma forma de entender o funcionamento genérico de qualquer sistema, como o das relações sociais e outros.

5 AlVAREZ, Maria Esmeralda Ballestero. Organização, sistemas e métodos. São Paulo: McGraw-Hill, 1990, p. 13.

6 LUHMANN, Niklas. Sistemas sociais: esboço de uma teoria geral. São Paulo: Vozes, 2016.

7 BASHUR, João Paulo. Distanciamento e Crítica: limites e possibilidades da teoria de sistemas de Niklas Luhmann. Tese apresentada ao Programa de Pós-Graduação do Departamento de Ciência Política da Faculdade De Filosofia, Letras e Ciências Humanas da Universidade de São Paulo, 2009.

8 O modelo da autopoiese decorre principalmente da teoria biológica de dois grandes cientistas, Humberto Maturana e Francisco Varela, os quais, referem que a palavra deriva do grego autos (por si próprio) e poiesis (criação, produção).

9 LUHMANN, Niklas. "The self-reproduction of law and its limits". In: TEUBNER, Gunther (ed.). Dilemmas of law in the Welfare State. Berlim/Nova York, Walter de Gruyter. 1986.

10 BACHUR, João Paulo. Inclusão e exclusão na teoria de sistemas sociais: aspectos críticos. BIB Revista Brasileira de Informacao Bibliografica em Ciencias Sociais, v. 73, p. 55-83, 2012. 
Segundo a interpretação de Rodrigues e Neves"11 "o sistema social existe e se reproduz como sistema de comunicação". Os mesmos autores indicam que, para Luhmann, "a comunicação não morre quando alguém morre e não nasce quando alguém nasce, ela perpassa a existência de qualquer um"12.

A comunicação promoveria o fenômeno indicado por Luhmann por "redução de complexidade" das informações ${ }^{13}$, decorrente de um raciocínio binário que o próprio sistema faz internamente: de aceitação ou rejeição de uma ideia. Quanto maior o número de elementos no interior do sistema, maior o número de relações possíveis entre os subsistemas. O número de possibilidades dentro dele passa a ser maior, podendo, inclusive, chegar a ponto de provocar sua autodiferenciação em subsistemas.

Tomando por base o próprio Direito, partindo do fato de que seja um subsistema social, sua existência depende da coerência de suas normas e sua complexidade ao longo do tempo necessitou ser reduzida por meio da diferenciação em outros subsistemas (economia, religião, política, ciência, educação, por exemplo). Assim, o sistema "Direito" diferenciou-se, primeiramente em público e privado, depois, em Direito Constitucional, Administrativo, Penal, Civil, Comercial, e assim sucessivamente. Esse processo revela a evolução e ao mesmo tempo a citada autorreprodução ${ }^{14}$ sob a perspectiva autopoiética. Sob este ponto de vista destaca-se Teubner ${ }^{15}$, que ressalta que no processo de redução das complexidades é que está a chave para a evolução do sistema do Direito. Quando atingem um elevado nível de complexidade, os sistemas produzem autonomias relativas, diferenciam-se, com o objetivo de reduzir essa complexidade. Toda diferenciação implica, além da redução de complexidade, na própria evolução do sistema. Assim, a capacidade evolutiva do Direito é percebida na variação dos seus conteúdos, na seleção e na estabilização da cultura jurídica. Para o autor, a inter-relação entre processo jurídico e cultura jurídica é, na verdade, a interação entre dois ciclos comunicativos.

Rosseto $^{16}$ (2011) traduz esses dois ciclos trazidos por Teubner ${ }^{17}$ da seguinte forma. O ciclo comunicativo representativo do processo jurídico constituiria a interação entre dois mecanismos: um de variação, que seriam as expectativas normativas, e outro mecanismo, o de seleção, indicado pelas decisões judiciais e suas interpretações. Já o ciclo comunicativo da cultura jurídica seria responsável por sua retenção, transmissão e formação de tradição. Assim, a transformação do Direito não decorreria do produto de um conflito social, mas da comunicação interna do sistema jurídico.

11 RODRIGUES, Leo Peixoto; NEVES, Fabrício Monteiro. Niklas Luhmann: a sociedade como sistema. Porto Alegre: Edipucrs, 2012, p. 59.

12 RODRIGUES, Leo Peixoto; NEVES, Fabrício Monteiro. Niklas Luhmann: a sociedade como sistema. Porto Alegre: Edipucrs, 2012, p.81.

13 LUHMANN, Niklas. "The self-reproduction of law and its limits". In: TEUBNER, Gunther (ed.). Dilemmas of law in the Welfare State. Berlim/Nova York, Walter de Gruyter, 1986. p. 112.

14 LUHMANN, Niklas. "The self-reproduction of law and its limits". In: TEUBNER, Gunther (ed.). Dilemmas of law in the Welfare State. Berlim/Nova York, Walter de Gruyter, 1986. p. 115-119.

15 TEUBNER, Gunther. O direito como sistema autopoiético. Lisboa, Fundação Calouste Gulbenkian, 1989. p. 113-114.

16 ROSSETTO, G.M.F. O Direito como sistema autopoiético na evolução jurídica da matriz teórica de Gunther Teubner. Revista Amicus Curiae, v. 7, 2011. p.13-14.

17 TEUBNER, Gunther. O direito como sistema autopoiético. Lisboa, Fundação Calouste Gulbenkian. p. 118-119. 
O Direito como sistema teria como função primordial manter estável as expectativas, ainda que estas sejam frustradas na prática. As expectativas são as normas jurídicas, que, assim, permanecem estáveis independentemente de uma eventual violação. Como sistema, a comunicação base do Direito para a sua diferenciação do meio ambiente ocorre pelo controle do código de preferência binário: "legal/ilegal", "lícito/ilícito", "constitucional/inconstitucional", dependendo da hierarquia da norma (que não deixa de ser uma hierarquia comunicativa). É esse código que permite a autodiferenciação do Direito e dentro do Direito.

Podemos entender, a partir das teorias de Luhmann e Teubner, que não é apenas a realidade social que produz o direito, mas o direito cria ou procura induzir a realidade social a partir de seus códigos. Parece-nos relevante indicar que, buscando referência justamente naquilo que o Direito indica relativamente à hierarquia das normas, o subsistema "Direito Constitucional" adquire de forma mais importante um caráter autorreferencial, justamente por ser norteador de decisões judiciais, normas e princípios. Possui, assim, uma estabilidade menos condicionada a outros contextos sociais, como política, religião ou moral.

Assim, além da própria estrutura semântica ou da organização do seu texto, seria possível perceber, por meio do entrelaçamento de suas referências internas, algum subsistema ou código específico emanado de nossa Carta Magna? Seria possível detectar códigos compartilhados ao longo de diferentes partes do texto constitucional?

É justamente utilizando a sugestão das "autorreferências" que vamos buscar responder essas perguntas por meio da utilização do recurso metodológico oferecido pela Análise de Redes aplicada ao conteúdo textual da Constituição.

\section{ANÁLISE DE REDES E A ELABORAÇÃO DA REDE DO TEXTO CONSTITUCIONAL}

A área de conhecimento das redes tem foco no estudo de relações complexas, tais como redes de encontradas no ecossistema, de computadores, de telecomunicação, sociais, entre tantas outras, revelando seu caráter eminentemente multidisciplinar. Avanços computacionais da era do Big Data conjugados com o crescimento das redes sociais proporcionam a ascensão deste campo. Como mostram Albert e Barabási ${ }^{18}$, estudos com esta metodologia analisam desde a World Wide Web (sites conectados por links) até a rede de elementos químicos de uma célula (conectados por reações). Há cerca de dez anos houve um aumento exponencial sobre a ciência das redes, tendo em vista a constatação de que o surgimento e a evolução das diferentes redes obedecem a princípios de organização comuns ${ }^{19}$.

18 ALBERT, R; BARABÁSI, A. L. Statistical Mechanics of Complex Networks. Reviews of Modern Physics. Vol. 74, n० 1, 2002. p. 47-97.

19 BARABÁSI, A.L. Graph theory. Network Science. 2012. Disponível em: <http://barabasilab.neu.edu/ networksciencebook/download/network_science_November_Ch2_2012.pdf $\geq$. Acesso em: 22 abr. de 2018. 
A análise de redes sociais, além da multidisciplinaridade, é uma ferramenta cuja vantagem "é a possibilidade de formalização gráfica e quantitativa de conceitos abstraídos a partir de propriedades e processos característicos da realidade social"20. Uma rede é composta por diferentes elementos, os principais são os "nós" e os "elos".

As análises tradicionais interpretam as redes como uma estrutura composta pela interação um conjunto de atores sociais, que seriam os "nós", que se interconectam por meio de relações relativamente estáveis e independentes, os "elos". Relativamente ao objeto deste estudo, trataremos os artigos da Constituição como os "nós", cada qual mantendo uma ou várias ligações com os demais, que representam seus relacionamentos e interações temáticas. Aqui, as relações serão materializadas por meio das referências existentes entre os dispositivos. Aplicação semelhante foi feita por Verrier²1, para os dispositivos do Código Civil francês.

Em nosso exercício, uma ligação entre dois artigos da Constituição existe quando um faz referência a outro, seja em seu caput ou parágrafos, incisos, alíneas, itens. Vejamos um exemplo, a partir da primeira ligação observada na Constituição Federal.

O primeiro artigo a fazer este tipo de referência é o art. $5^{\circ}$ (direitos e garantias fundamentais), quando remete ao art. 84 (competências do Presidente da República):

Art. $5^{\circ}$

XLVII - não haverá penas:

a) de morte, salvo em caso de guerra declarada, nos termos do art. 84, XIX;

Note que a ligação independe de qual artigo é a fonte ou o alvo da ligação. Analisemos outra situação, como a do art. $5^{\circ}$ que também é ligado ao art. 15 (perda ou suspensão de direitos políticos), porém a remissão parte do art. 15 para o art. 5 , e não o contrário:

Art. 15. É vedada a cassação de direitos políticos, cuja perda ou suspensão só se dará nos casos de:

IV - recusa de cumprir obrigação a todos imposta ou prestação alternativa, nos termos do art. 50, VIII;

Destaca-se que um artigo pode fazer referência a outro em mais de uma ocasião. Por exemplo, o art. 39 (servidores públicos) se refere 14 vezes a incisos do art. $7^{\circ}$ (direitos dos trabalhadores). Contemplamos esta distinção, mas ela tem um papel apenas coadjuvante na formação da rede,

20 SOUZA, Queila Regina; QUANDT, Carlos Olavo . Metodologia de análise de redes sociais. In: Fábio Duarte; Carlos Quandt; Queila Souza. (Org.). O Tempo das Redes. São Paulo: Perspectiva, p. 31-63, 2008.

21 VERRIER, J. Lexmex: Code civil des descritoses Français. 2012. Disponível em: www.lexmex.fr. 


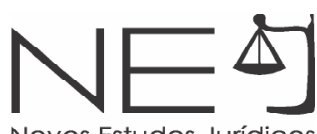

pois na forma visual da rede, a quantidade de referências entre dois artigos altera tão somente a espessura da ligação.

Cabe observar ainda que que a nossa adaptação metodológica para a construção da rede trata apenas dos casos em que os artigos fazerem referência explícita uns aos outros. Assim, por exemplo, o art. $5^{\circ}$ acaba por não estar entre os mais centrais da rede, porque não é tão citado textualmente quanto o art. 37. Isso não significa que seja "menos importante", pois o constituinte (ou, mais especificamente, a Comissão de Sistematização) pode ter entendido que o "efeito irradiante" dos direitos fundamentais tornasse desnecessária a citação explícita.

A partir do algoritmo escolhido 22 , tomaremos como métrica os seguintes parâmetros para a análise da rede gerada e geração de seu gráfico representativo:

a) Os pontos estão mais próximos quanto mais relacionados eles são, isto é, os artigos tendem a estar mais próximos quanto mais referenciados forem entre si;

b) O tamanho do ponto é proporcional à sua centralidade, isto é, os pontos representativos de artigos que mais referenciam outros ou são mais referenciados apresentam maior dimensão em relação aos outros.

Além desses aspectos, a análise de redes ainda possibilita identificação de distintos níveis de relações, caracterizadas pela observação de "comunidades" específicas dentro da estrutura principal. Barabási $^{23}$ define uma comunidade como um grupo de nós que tem maior probabilidade de se conectar entre si do que se conectar com outros nós.

Para Patty e Penn ${ }^{24}$, a noção de comunidade considera como uma rede indica diferença e semelhanças entre atores. Existem diversas maneiras diferentes de dividir uma rede em comunidadeso que é chamado de "detecção de comunidades" (community detection). Patty e Penn enxergam potencial para muitas aplicações de detecção de comunidades. Note que enquanto a centralidade permite classificar um nó de acordo com quão conectado ele é, o conceito de comunidade permite classificar a que grupo ele pertence.

Em nossa aplicação para a construção da rede dos artigos da Constituição, as comunidades são úteis por confrontarem a divisão formal do texto constitucional. Isto é, embora os artigos sejam divididos na Constituição em capítulos e seções, as comunidades permitiriam uma forma mais orgânica de visualizar os dispositivos, uma vez que é determinada pela menção entre eles no texto da Constituição. Além da visualização, uma vez detectada, cada comunidade poderá ser avaliada em termos dos seus "códigos comunicativos", distinguindo-se, também, em termos de subsistemas.

22 Neste trabalho foi usado o software Gephi e algoritmo de layout conhecido por ForceAtlas2. Mais detalhes sobre a ferramenta consultar JACOMY, M; VENTURINI, T; HEYMANN, S; \& BASTIAN, M. ForceAtlas2, a Continuous Graph Layout Algorithm for Handy Network Visualization Designed for the Gephi Software, 2014.

23 BARABÁSI, A. L. Network Science. Cambridge: Cambridge University Press. 2016

24 PATTY, J. W., \& PENN, E. M. Network Theory and Political Science. In: Victor, J. N., Montgomery, A. H., \& Lubell, M. (Org.). The Oxford Handbook of Political Networks. New York: Oxford University Press. 2017 
Novos Estudos Jurídicos

A Figura 1 apresenta a rede construída após os procedimentos descritos. Como salientado anteriormente, cada ponto é um artigo da Constituição, que se conecta com outro se em algum de seus dispositivos faz referência a ele, ou, alternativamente, se é referenciado em algum dos dispositivos do outro artigo.

Figura 1 - Teia de artigos - Comunidades da Constituição

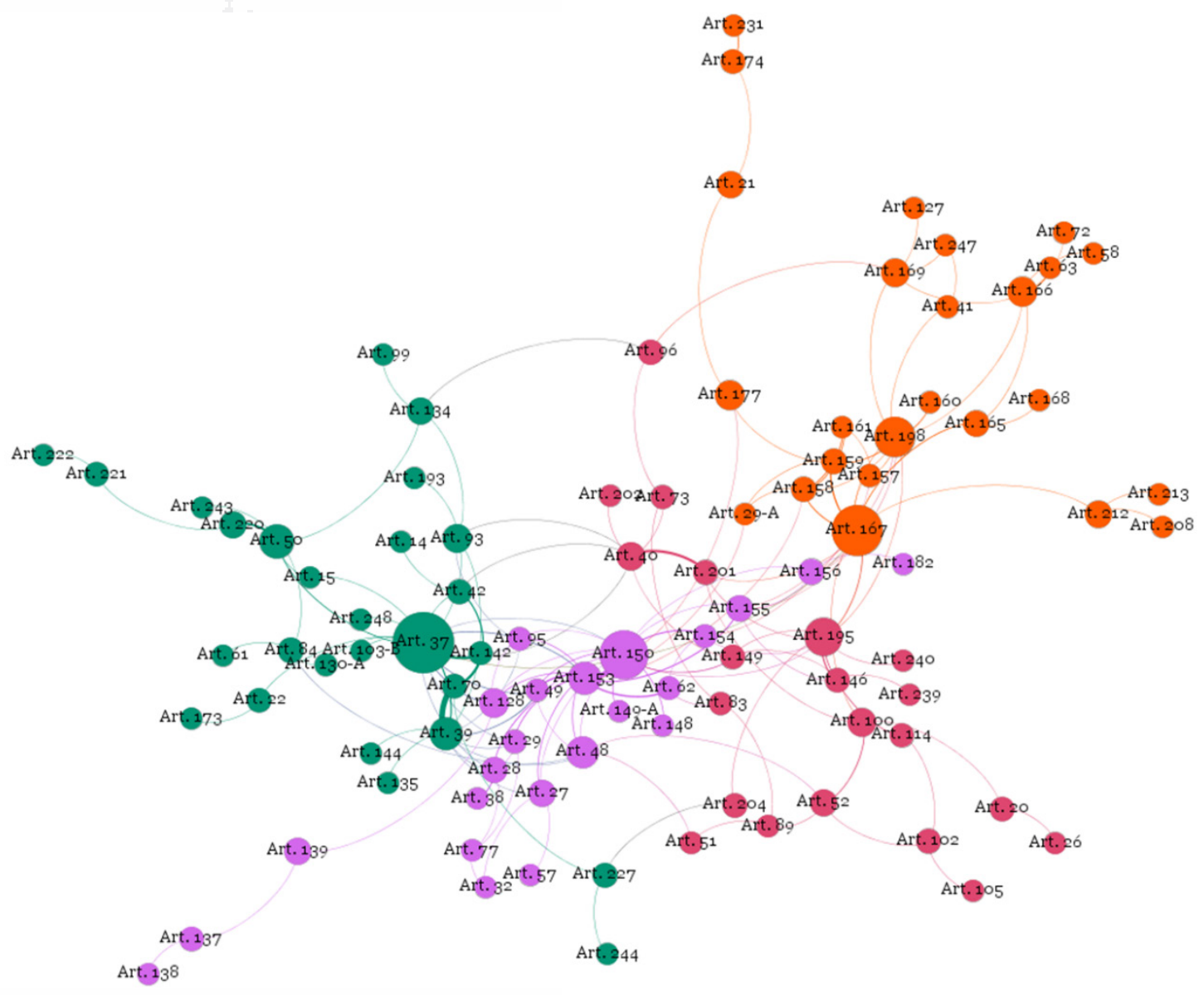

Fonte: Elaboração própria.

\section{DESCRIÇÃO DA REDE ELABORADA}

Pelos parâmetros de construção por nós adotados, ao todo foram observadas 177 ligações entre 108 artigos. A seguir, destacaremos as características dessas comunidades e suas ligações com base nos conceitos de análise de rede.

\subsection{PARÂMETRO DE PROXIMIDADE}

Para evidenciar como artigos mais próximos tendem a se avizinhar no gráfico, tomemos como exemplo o art. 150 (limitações ao poder de tributar) e o art. 153 (competências da União de instituir impostos). Eles são facilmente identificáveis na Figura 1: são dois pontos maiores, próximos um ao outro no meio da rede. 
O art. 150 remete 8 vezes ao art. 153, o que explica a proximidade na rede. Por outro lado, note a ampla distância entre o art. 222 (propriedade de empresas de comunicação), no canto esquerdo inferior da imagem, e o art. 213 (recursos da educação), no canto direito. Apesar da proximidade topográfica destes dispositivos relativamente à sua ordem numérica na Constituição (separados por apenas 8 artigos, art. 214 ao art. 221), além de não fazerem referências entre si, também não apresentam qualquer conexão indireta na rede.

Isso explica a distância entre eles na rede, e também fornece um exemplo didático para formar uma melhor intuição e a lógica do algoritmo. Note que para "chegar" do art. 222, na esquerda, ao 213, na direita, passamos pela conexão do art. 222 com o art. 221 (princípios da produção e programação de emissoras de rádio e TV), do art. 221 com o art. 220 (sobre comunicação), do art. 220 com o art. $5^{\circ}$ (direitos e garantias fundamentais), do $5^{\circ}$ com o art. 37 (Administração Pública), do art. 37 com o art. 167 (vedações em matéria orçamentária), do art. 167 com o art. 212 (piso orçamentário da educação), e, finalmente, do art. 212 com o art. 213.

A rede, portanto, apresenta uma configuração que faz sentido, pois, de fato aproxima artigos semelhantes e que se relacionam e distancia artigos distintos e que não se relacionam.

\subsection{PARÂMETRO DE CENTRALIDADE}

Esta talvez seja a característica mais interessante em termos de visualização. Como um aeroporto importante que conecta por meio de seus voos outros aeroportos de diferentes regiões, os pontos são mais centrais quanto mais ligações forem geradas por meio deles. Além disso, na metodologia aqui empregada, são mais centrais os pontos que se conectam com pontos mais diversos, ou seja, pontos menos conectados entre si ${ }^{25}$. A Tabela 1 lista os 10 artigos da Constituição mais centrais na rede.

Tabela 1 - Artigos que apresentam maior número de ligações na rede

\begin{tabular}{|l|l|}
\hline Art. 37 & Disposições gerais sobre Administração Pública \\
\hline Art. 167 & Vedações em matéria orçamentária \\
\hline Art. 150 & Limitações ao poder de tributar \\
\hline Art. 198 & Sistema Único de Saúde \\
\hline Art. 195 & Financiamento da Seguridade Social \\
\hline Art. 5 & Direitos e garantias fundamentais \\
\hline Art. 39 & Servidores públicos \\
\hline Art. 153 & Competências da União de instituir impostos \\
\hline Art. 48 & Competências do Congresso Nacional \\
\hline Art. 166 & Processo legislativo orçamentário \\
\hline
\end{tabular}

Fonte: Elaboração própria.

25 É importante novamente frisar que a centralidade é um conceito da análise de redes que indica maior número de vínculos e ligações. Maior centralidade não quer dizer maior relevância ou mais importância relativamente ao conteúdo, aos princípios e ao próprio Direito. 
Mantendo a analogia, para um mesmo número de voos, é mais central o aeroporto que conecta regiões distintas do que um aeroporto que conecta voos entre uma mesma região. Outra analogia seria considerar um indivíduo popular como aquele que não apenas possui muitos amigos, mas tem grupos de amigos distintos.

Por exemplo, o art. 142 (Forças Armadas) faz muitas referências ao art. $7^{\circ}$ (direitos dos trabalhadores) e ao art. 37 (Administração Pública), todas dentro da esfera de direitos ligados ao trabalho, seja dos trabalhadores da iniciativa privada, do servidor ou do militar - como férias remuneradas. Já o art. 167 (vedações em matéria de orçamento) é mais central: faz referência a 12 artigos tão distintos quanto o próprio 37 (Administração Pública), 62 (medidas provisórias), o 198 (Sistema Único de Saúde, SUS), o 201 (previdência social), ou o 212 (piso da educação). O art. 142 não é, portanto, um artigo central, enquanto o art. 167 aparece como um dos artigos mais centrais desse esquema da Constituição.

O algoritmo gerador da rede também alcançou a elaboração de nove comunidades distintas por um algoritmo. Algumas são muito intuitivas, pois, relembrando, uma comunidade é um grupo de pontos que possui mais ligações entre si do que com os demais. Destacamos as quatro grandes comunidades representadas por diferentes cores na Figura 1.

A maior dela possui 25 artigos e aparece em tom esverdeado no lado esquerdo da rede, tendo como ponto central o art. 37 (disposições gerais sobre administração púbica). A segunda, à direita, em tom alaranjado, com 24 artigos, é centralizada pelo art. 167 (vedações em matéria orçamentária). A terceira, maior, com 21 artigos, aparece no centro da rede em tom lilás e tem como ponto central o art. 150 (limitações ao poder de tributar). Também com 21 artigos, em tom avermelhado, está a comunidade ao redor do art. 195 (financiamento da Seguridade Social).

Residualmente, existem ainda comunidades de artigos que não são conectados com a teia central descrita. Trata-se de artigos que referenciam ou são referenciados por outros artigos no texto da Constituição, mas nenhum deles se conecta com os artigos que integram a rede principal.

Por exemplo, o art. 94 (quinto constitucional para advogados em tribunais), o art. 104 (Superior Tribunal de Justiça), o art. 111-A (Tribunal Superior do Trabalho) e o art. 15 (tribunais regionais do trabalho) se relacionam, mas nenhum deles se relaciona com os outros dispositivos da Constituição. O mesmo ocorre com os demais casos detectados.

Para facilitar a compreensão, reproduzimos a rede por meio da Tabela 2, que lista os artigos que compõem cada comunidade, ranqueados por centralidade. 
Tabela 2 - Comunidades mapeadas

\begin{tabular}{|c|c|c|c|c|}
\hline Comunidade 1 & Comunidade 2 & Comunidade 3 & Comunidade 4 & Comunidades \\
\hline Art. 37 & Art. 167 & Art. 150 & Art. 195 & sem conexão \\
\hline Art. $5^{\circ}$ & Art. 198 & Art. 153 & Art. 201 & com a teia \\
\hline Art. 39 & Art. 166 & Art. 48 & Art. 40 & central \\
\hline Art. 93 & Art. 169 & Art. 128 & Art. 204 & Comunidade 5 \\
\hline Art. 220 & Art. 212 & Art. 27 & Art. 146 & Art. 94 \\
\hline Art. 134 & Art. 165 & Art. 139 & Art. 114 & Art. 104 \\
\hline Art. 42 & Art. 156 & Art. 155 & Art. 149 & Art. 111-A \\
\hline Art. 227 & Art. 159 & Art. 28 & Art. 202 & Art. 115 \\
\hline Art. 204 & Art. 96 & Art. 137 & Art. 239 & Comunidade 6 \\
\hline Art. $7^{\circ}$ & Art. 158 & Art. 29 & Art. 240 & Art. 36 \\
\hline Art. 22 & Art. 157 & Art. 95 & Art. 100 & Art. 34 \\
\hline Art. 221 & Art. 41 & Art. 154 & Art. 52 & Art. 35 \\
\hline Art. 142 & Art. 247 & Art. 62 & Art. 73 & Comunidade 7 \\
\hline Art. 15 & Art. 161 & Art. 49 & Art. 89 & Art. 223 \\
\hline Art. 173 & Art. 63 & Art. 77 & Art. 51 & Art. 64 \\
\hline Art. 14 & Art. 72 & Art. 32 & Art. 20 & Comunidade 8 \\
\hline Art. 103-B & Art. 127 & Art. 57 & Art. 26 & Art. 225 \\
\hline Art. 193 & Art. 182 & Art. 38 & Art. 102 & Art. 215 \\
\hline Art. 99 & Art. 160 & Art. 138 & Art. 105 & Comunidade 9 \\
\hline Art. 135 & Art. 58 & Art. 148 & Art. 96 & Art. 242 \\
\hline Art. 144 & Art. 168 & Art. 149-A & & Art. 206 \\
\hline Art. 222 & Art. 213 & & & \\
\hline Art. 243 & Art. 208 & & & \\
\hline Art. 244 & Art. 29-A & & & \\
\hline Art. 248 & & & & \\
\hline
\end{tabular}

Fonte: elaboração própria

A partir da observação dos artigos mais centrais e de suas respectivas comunidades, passaremos à sua análise, procurando entender, do ponto de vista da teoria de Luhmann e Teubner, como cada uma dela comunica e se diferencia como subsistema do Direito Constitucional.

\section{ANÁLISES DOS RESULTADOS}

\subsection{ADMINISTRAÇÃO PÚBLICA}

Segundo Britto ${ }^{26}$, o capítulo devotado à Administração Pública foi uma das mais belas novidades da Constituição brasileira de 1988. Para o autor, trata-se de um subconjunto normativo que se inicia com o art. 37, inspirado fortemente no título IX da Constituição portuguesa de 1976. Certamente, o ministro trata da sequência de dispositivos incluídos na organização do Capítulo VII do Título III da nossa Constituição. Ocorre que no mapeamento por nós realizado, observamos que as referências a esse artigo se comunicam por todo o texto constitucional.

26 BRITTO, Carlos Ayres. Comentário ao artigo 37, caput, In CANOTILHO, J. J. Gomes; MENDES, Gilmar F.; SARLET, Ingo W.; STRECK, Lenio L. (Coords.). Comentários à Constituição do Brasil. São Paulo:Saraiva/ Almedina, 2013, p.884. 
Figura 2 - A Administração Pública e suas conexões textuais na Constituição

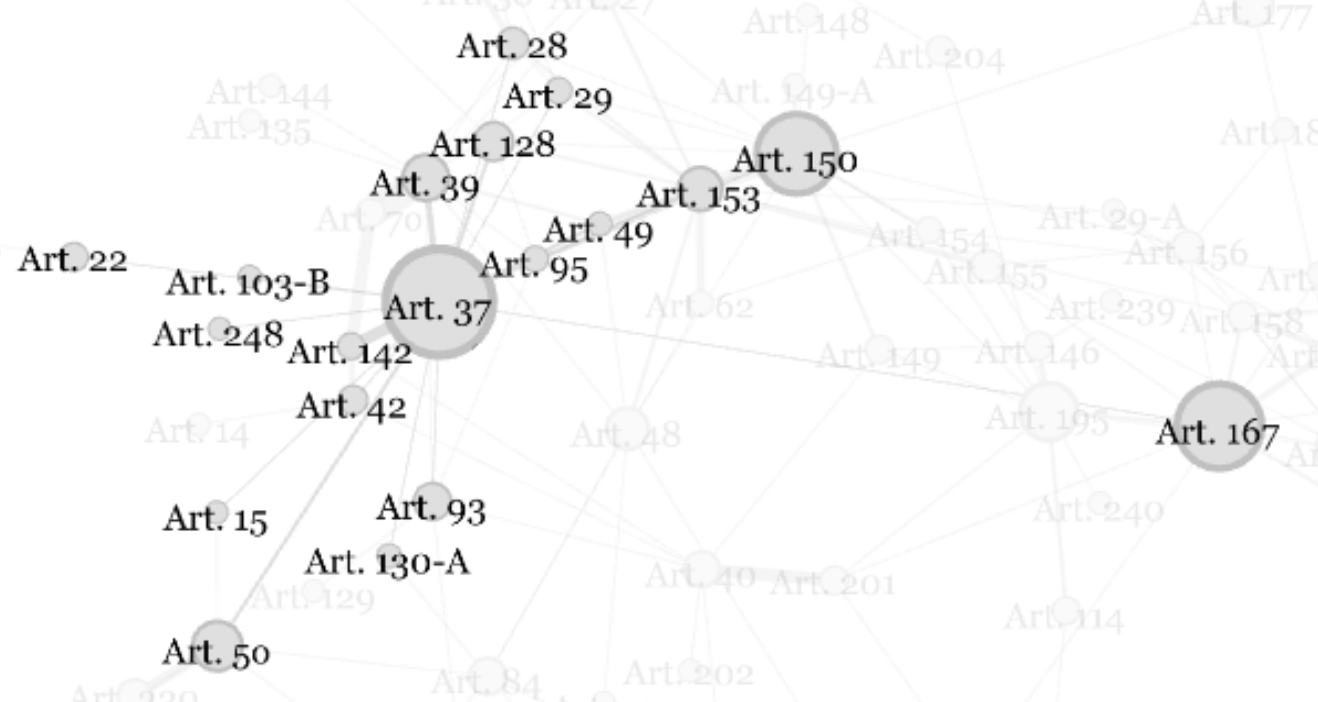

Fonte: elaboração própria

Do seu tratamento para improbidade administrativa citada no art. 15 (perda e suspensão de direitos políticos) às normas gerais sobre licitações e contratos citadas no art. 22 (competências privativas da União), o art. 37 trata de ampla gama de temas nos 22 incisos de seu caput e em seus 12 parágrafos. Entretanto, são mais lembrados, curiosamente, os seus incisos X e XI, referentes à remuneração dos servidores públicos - respectivamente a revisão anual e o teto. Eles são lembrados nos arts. 28 (governadores), 29 (Municípios), 39 (servidores públicos), 49 (competências exclusivas do Congresso Nacional, no caso a de fixar subsídios para Deputados, Senadores, Presidente e Ministros), 93 (estatuto da magistratura, no caso o subsídio de Ministros de Tribunais Superiores), 95 (garantias de juízes), 128 (Ministério Público) e 142 (Forças Armadas). É bastante simbólica e significativa a centralidade de um artigo sobre Administração Pública em nosso esquema. Algumas hipóteses podem explicar essa gama de citações ao dispositivo em tantos e tão diversos dispositivos da Constituição.

Em primeiro lugar, isso pode decorrer da força de sindicatos e outras entidades corporativas na própria constituinte. Assim, por exemplo, diversos direitos dos servidores públicos, referenciados no art. 37, são retomados em outros capítulos, como em relação às forças de segurança pública. Em sentido semelhante, a força de representações de categorias de servidores públicos pode ter representado uma tendência a um "inchaço" do capítulo de Administração Pública com regras sobre remuneração, o que tornou necessária a remissão em vários outros pontos da Constituição. Também não parece ser à toa o fato de outro artigo que está entre os dez mais centrais ser o art. 39 (sétima posição), que trata especificamente dos direitos dos servidores públicos. 
Outra explicação para esse fenômeno pode ser retirada com base na manifestação do poder constituinte derivado, e não originário. Isso porque, especialmente em virtude das reformas previdenciárias (Emendas à Constituição - EC ns 20, de 1998; 41, de 2003; e 47, de 2005) e do Judiciário (EC n⿳ 45, de 2004), houve a paulatina aproximação entre as regras dos servidores públicos e de determinadas categorias especiais, como agentes políticos (stricto sensu), magistrados e membros do Ministério Público. Muitas vezes, essa igualação de regras (inclusive com a expressa submissão ao teto remuneratório, etc.) deu-se por expressa remissão ao capítulo de Administração Pública, em geral, e ao art. 37, de forma mais frequente. É o caso, por exemplo, da remissão dos artigos que tratam sobre o Conselho Nacional de Justiça (art. 103-B) e do Conselho Nacional do Ministério Público (art. 130A) aos princípios do art. 37; assim como a aplicação aos magistrados das regras de aposentadoria dos servidores (art. 93, VI, c/c art. 40) - todas essas remissões introduzidas por obra de reforma da Constituição. Outro aspecto que chama a atenção é a multiplicidade de temas abordados no art. 37. Nele são tratados os princípios da Administração Pública (caput e $\S 1^{\circ}$ ), regras de acesso a cargos públicos (incisos I a V e $\S 2^{\circ}$ ), questões remuneratórias (incisos $\mathrm{X}$ a XIV), diretrizes de licitações (inciso XXII), além de temas como improbidade administrativa $\left(\S 4^{\circ}\right)$, responsabilidade civil do estado $\left(\S 6^{\circ}\right)$, contrato de gestão $\left(\S 8^{\circ}\right)$. Isso faz com que o art. 37 seja citado por uma gama múltipla de dispositivos nos mais diversos temas da Constituição, o que o torna tão central na análise aqui empreendida.

Finalmente, não se pode descartar a questão ideológica. Em um país cujas constituições sempre reservaram um lugar de destaque ao Estado, a Constituição de 1988 inovou ao começar suas disposições pelos direitos e garantias fundamentais (arts. $5^{\circ}$ a 17), e não pela organização do Estado. Inevitavelmente, porém, uma "herança cultural", por assim dizer, fez com que, conscientemente ou não, o constituinte desse aos dispositivos sobre o Estado, o Governo e Administração Pública um papel central - se não do ponto de vista "geográfico", ao menos sob o aspecto da quantidade de remissões. Nesse sentido, não é estranho que os três primeiros pontos centrais tratem de questões eminentemente de organização do Estado e dos Poderes (lato sensu), como Administração Pública (art. 37), finanças públicas (art. 167) e tributação (art. 150).

Finalmente, além dos aspectos históricos, evolutivos e instrumentais que explicam a centralidade do art. 37, no seu próprio caput se depreende como que a comunidade criada em seu entorno cria o subsistema com comunicação própria, que é o dos princípios da "legalidade", impessoalidade", "moralidade", "publicidade" e "eficiência". Como ressalta Ayres Britto, "princípios que submetem o Estado quando da criação legislativa de órgãos e entidades, assim como submetem todo e qualquer Poder estatal quando do exercício da atividade em si de administração pública". O mesmo autor arremata: "Com o aporte de tais princípios, a começar pelo da legalidade, a nossa Constituição atesta que toda atividade estatal-administrativa é um gravitar na órbita da lei". Desta forma, a comunidade "Administração Pública" tem identidade própria e diferenciação suficiente para ser observada como um subsistema comunicativo balizador de comportamentos e autorreferenciado. 


\subsection{VEDAÇÕES SOBRE A ALOCAÇÃO E UTILIZAÇÃO DE RECURSOS ORÇAMENTÁRIOS}

O segundo maior coeficiente de centralidade calculado para nosso esquema do texto constitucional é o do art. 167, que estabelece vedações em matéria orçamentária. Este dispositivo se conecta com outros 12 artigos. Ele veda a vinculação de receitas, mas excepciona o caso da saúde (art. 198), os dos fundos de participação de Estados e Municípios (arts. 158 e 159) e o das operações de antecipação de receita (art. 165).

Figura 3 - Restrições sobre a alocação e utilização de recursos orçamentários e suas conexões textuais na Constituição

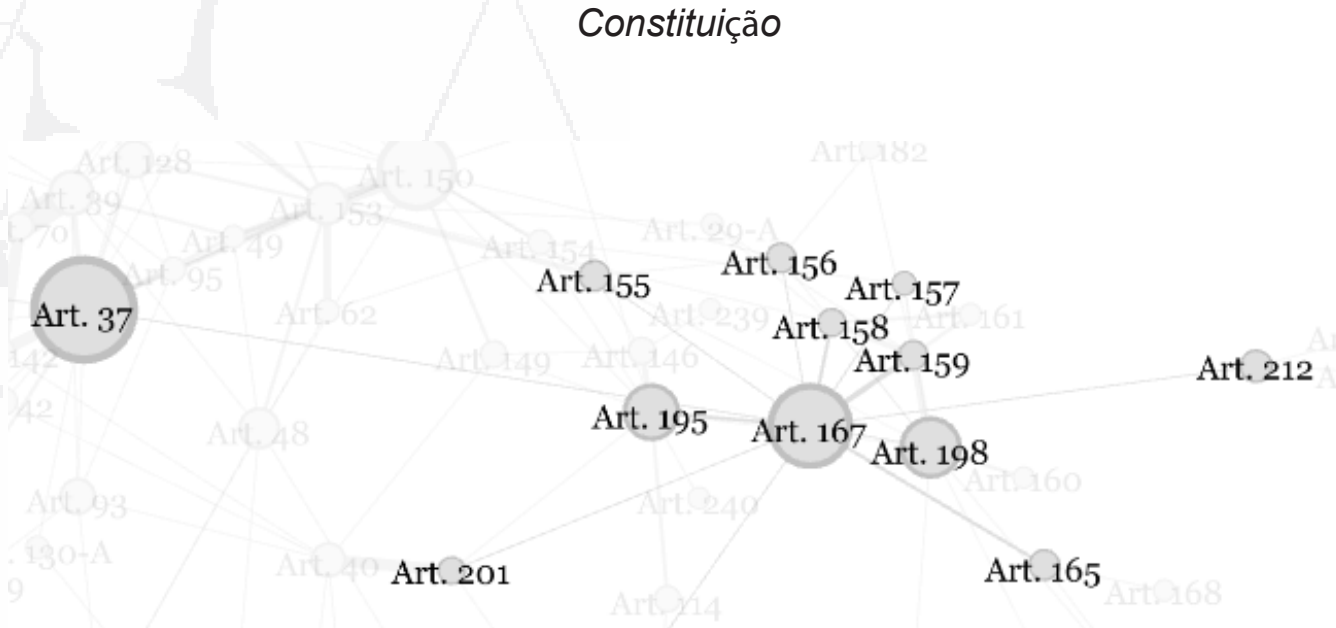

Art. 100

Fonte: elaboração própria

Seu escopo é ainda mais amplo: veda o uso das contribuições previdenciárias (art. 195) para o pagamento de despesas diferentes dos benefícios do regime geral de previdência social (art. 201) e restringe o uso de abertura de crédito extraordinário pelo Presidente em caso de urgência (art. 62).

Em relação ao art. 167, igualmente, várias explicações (possivelmente complementares) se desenham para visualizá-lo não apenas como comunidade de artigos, mas como subsistema constitucional do tipo luhmanniano. Primeiramente, há uma consequência de centralidade de normas sobre finanças públicas, à medida que cresce a positivação de direitos fundamentais sociais (prestacionais) na assim chamada "Constituição Cidadã". Isso porque, como se sabe, a demanda por recursos financeiros é bastante mais intensa para a efetivação dessa categoria de direitos, quando comparada com a implementação de outros direitos também fundamentais (especialmente os direitos individuais). Assim, se a Constituição de 1988 ampliou substancialmente as previsões de direitos a serem assegurados pelo Estado com a finalidade de assegurar o bem-estar dos indivíduos, torna-se quase natural que os dispositivos sobre finanças públicas se tornem (ainda 


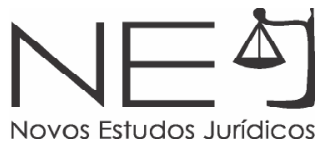

mais) centrais. Essa hipótese parece ser corroborada pelo fato de que a lista dos dez artigos mais centrais, em nossa análise, inclua os arts. 198 (direito à saúde, quarta posição), 195 (financiamento da seguridade social, quinta posição), além do próprio art. 166 (processo legislativo orçamentário, décima posição). É impactante, aliás, verificar que o dispositivo sobre o processo legislativo especial orçamentário consegue ser mais central do que o próprio dispositivo que trata em regra sobre o processo legislativo (art. 59).

Outro aspecto que explica a centralidade do art. 167 é o fato de a questão orçamentária ser fundamental tanto para a organização do Estado (são regras que precisam ser seguidas pelos demais entes federativos, por simetria), quanto para a separação de poderes (nas relações do Executivo com os demais poderes - arts. 168, 99, 127 - bem como na definição das atribuições do Poder Executivo e do Poder Legislativo). Nesse contexto, sem realizar juízos de mérito sobre casos concretos, não deixa de ser peculiar o fato de que recentemente se realizou o impeachment de uma Presidente da República por basicamente descumprimento de regras orçamentárias (art. 167). Isso pode significar que, ao menos de forma declarada, o respeito às questões de orçamento é também considerado central para o modo como o Legislativo vê os atos do Executivo. Desta forma, o subsistema que gira em torno do art. 167 apresenta uma comunicação muito própria: a da necessidade da legalidade orçamentária que se firma no princípio do Estado de Direito, amalgamando-se à própria ideia de liberdade ao promover a limitação do poder do Estado e, ao mesmo tempo, de direcionamento das atividades administrativas para a efetivação de direitos fundamentais e sociais ${ }^{27}$.

\subsection{LIMITAÇÕES DO PODER DE TRIBUTAR: LEGALIDADE E PROTEÇÃO CONTRA ABUSOS DO ESTADO}

O terceiro artigo mais central da rede de comunidades é o art. 150, sobre as limitações ao poder de tributar. Tal dispositivo sempre foi, na história brasileira, bastante relevante. Com algumas mudanças, o tema era tratado já no art. 20 (geograficamente "privilegiado", portanto) da Constituição de 1967. Essa linha de "privilégio" das limitações ao poder de tributar remonta à própria Constituição de 1891, que tratava do tema logo no art. 11.

Dessa maneira, não é exatamente surpreendente essa posição de centralidade do tema na Constituição em vigor, ainda mais se percebermos que o Sistema Tributário Nacional foi um dos temas que ganhou mais relevo na Constituição de 1988, tendo merecido uma Comissão específica na constituinte (Comissão de Sistema Tributário, Orçamento e Finanças) e reconhecidamente tendo ganhado em complexidade e multiplicidade de temas. É muito lembrado em outros artigos o seu inciso II, que veda o tratamento diferenciado dos contribuintes por profissão, destacado para deputados estaduais (art. 27); governadores e secretários (art. 28); prefeitos (art. 29); servidores (art. 37); ministros do Supremo Tribunal Federal (art. 48); Deputados, Senadores, Presidente e Ministros (art. 49); juízes (art. 95) e promotores e procuradores (art. 128).

27 CALIENDO, Paulo. Comentário ao artigo 167, caput, In Canotilho, J. J. Gomes; Mendes, Gilmar F.; Sarlet, Ingo W.; Streck, Lenio L. (Coords.). Comentários à Constituição do Brasil. São Paulo:Saraiva/Almedina, 2013, p.884. 
Figura 4 - Limitações ao poder de tributar e suas conexões textuais na Constituição

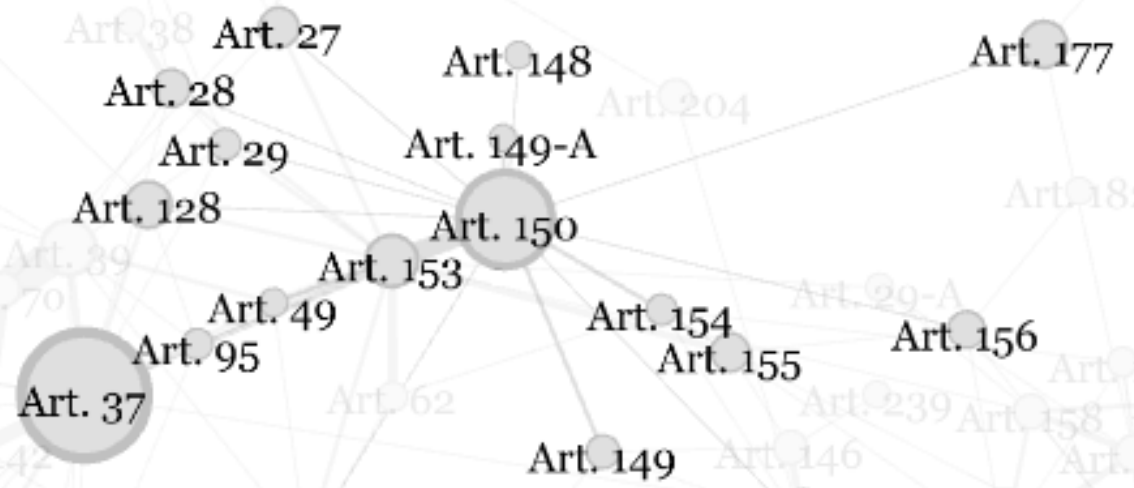

Art. 48

Art. 195

Fonte: elaboração própria

Também é muito relacionado o inciso III do art. 150, que trata dos princípios da anterioridade e noventena, vedando a cobrança de tributos no mesmo ano em que foi instituído (anterioridade) ou sem antecedência de 90 dias (noventena). Os princípios são referenciados pelos dispositivos que tratam das contribuições sociais e de intervenção no domínio econômico (CIDE) (arts. 149, 177 e 195), da taxa municipal de iluminação pública (art. 149-A), e do Imposto sobre Circulação de Mercadorias e Serviços (ICMS) sobre combustíveis (art. 155).

Outra ligação importante é com os temas federativos. A repartição de competências em matéria tributária, por exemplo, está na lista dos dez artigos mais centrais (na oitava posição, representada pelo dispositivo que enumera os impostos de competência da União), e a própria disposição sobre os limites ao poder de tributar exerce papel relevante nesse setor: basta ver, por exemplo, que uma das regras mais importantes para a Federação e o equilíbrio federativo encontra-se no art. 150 (inciso VI): a chamada imunidade tributária recíproca.

Demais disso, entendemos que o fator mais relevante é a compreensão da íntima conexão entre as limitações ao poder de tributar e os direitos fundamentais. Nesse contexto, tais limitações passam a ser lidas como verdadeiras garantias institucionais ou pessoais dos direitos fundamentais à propriedade (princípio do não confisco, art. 150, IV), à liberdade (princípio da estrita legalidade, art. 150, I), à igualdade (proibição de tratamento desigual entre contribuintes, art. 150, II) e da própria segurança jurídica (princípios da anterioridade e da não retroatividade, art. 150, III, alíneas "a" a "c").

Observa-se um vínculo importante com a condição da ação do Poder Público (em sintonia com o art. 37), especialmente no que tange ao reconhecimento da legalidade como relevante instrumento que contribui para a segurança e certeza do Direito. Afinal, legalidade é também um instrumento 
de proteção contra investidas decorrentes do exercício do poder. Como cita Greco 28 "é inafastável elemento de defesa do cidadão no relacionamento com o Poder Público, inclusive com o Fisco. Exigir a legalidade significa que novas obrigações ou restrições de direitos só podem emanar diretamente da lei e não de norma que lhe seja infraordenada".

\subsection{FINANCIAMENTO DA SEGURIDADE SOCIAL - ÊNFASE SOBRE PREVIDÊNCIA E ASSISTÊNCIA}

Observando a evolução histórica dos textos constitucionais, a inserção do tema do financiamento da Seguridade Social norma é inédita, não tendo aparecido em qualquer outra disposição constitucional ou infraconstitucional de que se tem notícia, apenas no que tange ao custeio da Previdência Social previsto na Lei Orgânica da Previdência (Lei n 3.807, de 26 de agosto de 1960), quanto na Consolidação das Leis da Previdência Social (Decreto n. 89.312, de 23 de janeiro de 1984). Desta forma, a originalidade foi justamente estabelecer uma espécie de salvaguarda para um conceito mais amplo de segurança de direitos, incorporando Saúde, Previdência e Assistência Social29. No entanto, chama a atenção que essa comunidade mapeada ainda reforça de forma significativa uma interconexão entre diferentes dispositivos que ressaltam comunicações específicas e especialmente voltadas para mensagens de salvaguardas relativamente ao sistema de Seguridade Social.

Figura 5 - Financiamento da Previdência e Assistência Social e suas conexões textuais na Constituição

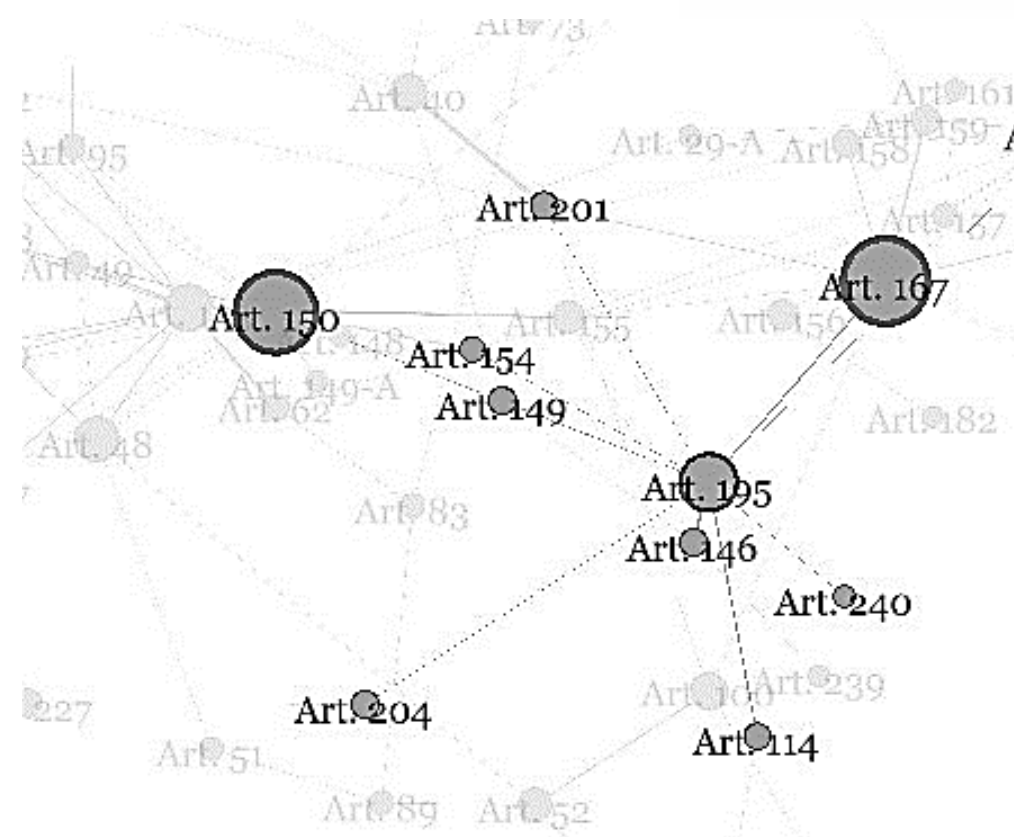

Fonte: elaboração própria

28 GRECO, Marco Aurélio, Comentário ao artigo 150, in CANOTILHO, J. J. GOMES; MENDES, Gilmar F.; SARLET, Ingo W.; STRECK, Lenio L. (Coords.). Comentários à Constituição do Brasil. São Paulo:Saraiva/Almedina, 2013, p.1742-1744.

29 CORREIA, Marcus Orione Gonçalves, Comentário ao artigo 195, in Canotilho, J. J. Gomes; Mendes, Gilmar F.; Sarlet, Ingo W.; Streck, Lenio L. (Coords.). Comentários à Constituição do Brasil. São Paulo:Saraiva/Almedina, 2013, p.1854 
Ressaltamos o conjunto de regras específicas atinentes ao conjunto de direitos estabelecidos pela Previdência Social (art. 201) e sua intersecção com a Previdência dos Servidores Públicos (art. 40). Ao mesmo tempo que o princípio da solidariedade contributiva é reforçado por essa ligação, ao mesmo tempo em que se define em que termos os direitos aos benefícios são estruturados e serem assegurados pelas suas fontes de custeio. Ressalta-se, nessa estrutura, a vinculação da Previdência Complementar (art. 202) como aspecto relevante para assegurar que o custeio do sistema de proteção social pode também ser acrescido de contribuições adicionais facultativas.

Outra mensagem extraída dessa comunidade é o respaldo que se oferece ao sistema de Assistência Social (art. 204). Além de reforçar a inovação do custeio dessa atividade estatal, o mencionado artigo liga-se ao art. 195 quando prevê diretrizes para organização, com ênfase para a descentralização político-administrativa da assistência social e a participação da população na formulação da política de assistência social. Um mecanismo inovador e renovador do seu texto foi introduzido pela Emenda Constitucional n 42, de 19 de dezembro de 2003, franqueando aos Estados e ao Distrito Federal a possibilidade de vincular parte de sua receita tributária líquida a programas de assistência social. A mensagem é clara: induzir governantes a institucionalizar seus programas garantindo-Ihes parte específica de sua arrecadação.

Também chama a atenção para o fato de estabelecer que as contribuições sociais de que trata o art. 149, devam estar estabelecidas por meio de lei complementar (art. 146), mas o que chama mais atenção, embora estejaestabelecido o princípio da noventena, excetua-se o princípio da anuidade (art. 195, § $6^{\circ}$ ) para a efetivação do custeio da Seguridade Social, ou seja, pode ser arrecadada no mesmo exercício financeiro em que haja sido publicada sua lei instituidora.

Finalmente, outra mensagem oferecida por essa comunidade é a destacada pela competência da Justiça do Trabalho para julgar e executar de ofício os pedidos de recolhimento das contribuições previdenciárias durante o contrato de trabalho (art. 114, inciso VII). Tal iniciativa gerou elemento no nosso ordenamento jurídico com o intuito de combater a sonegação e consequentemente aumentar a arrecadação das contribuições previdenciárias. Desse modo, observa-se que essa comunidade realiza comunicação na forma de um subsistema que não apenas cuida sobre as formas de custeio, mas como elas devem dialogar com os direitos que têm de garantir, e de algumas prioridades que tal forma de custeio têm relativamente a outras formas de arrecadação.

Chama a atenção deste subsistema não incorporar diretamente a Saúde (art. 198). Nota-se que o art. 198 é o quarto artigo mais "central" do ponto de vista da metodologia de redes por nós adotada. No entanto, tal condição não foi suficiente para que tal artigo criasse em seu entorno uma comunidade específica. A explicação parece estar vinculada ao fato de que a conformação textual da Constituição no que tange à Saúde está mais facilmente circunscrita dentro da lógica sequencial estabelecida pelo Constituinte, indicando menos necessidade de conexões mais diversas com outras partes temáticas. 
Um dos mais valorizados princípios de interpretação constitucional é o da unidade da Constituição, que observa seu texto como um sistema único, repleto de princípios e regras. A ele também associado o princípio da interpretação por efeito integrador, pelo qual se deve priorizar os critérios que favoreçam a integração política e social quando da resolução de problemas jurídico-constitucionais. Tal perspectiva, amplamente difundida e valorizada no âmbito do Direito Constitucional, não elimina o fato de que o sistema constitucional não precisa ser monolítico para a harmonia de sua interpretação.

Neste trabalho, fortalecendo a noção de que não apenas o Direito, mas também o próprio Direito Constitucional, é um sistema constituído por vários segmentos ou subsistemas, sustentamos que é possível obter informações relevantes não apenas da organização formal da Carta Magna, dentro de uma lógica funcional e temática, mas também da sincronização e mapeamento de suas referências internas, as quais também formam subsistemas ou comunidades, na metodologia de redes que aplicamos. Dessa forma, longe de estabelecer qualquer hierarquia entre os dispositivos, o método aplicado permitiu a visualização de mais possibilidades dentro de um sistema complexo como o da nossa Carta Constitucional.

Não se pode deixar de reconhecer uma relação entre os próprios arts. 37, 167, 150 e 195. Todos eles tratam, direta ou indiretamente, de questões financeiras, seja em relação à despesa (art. 167), aos limites (art. 37, XI, por exemplo) dela, e à forma de financiamento (arts. 150 e 195). É coerente, portanto, que, dos dez artigos mais centrais, ou seja, que mais concentram referências internas, sete deles tratam direta ou indiretamente de questões financeiras, tributárias ou gerenciais. Esses três hubs estão também interligados entre si por questões lógicas e da cronologia das próprias finanças públicas: a arrecadação, a despesa e, dentro dessa, especialmente a gestão administrativa dos recursos.

A propósito, pode-se também verificar que todos os dispositivos mais centrais guardam entre si a característica da interdisciplinaridade, por assim dizer: tangenciam em geral temas de separação de poderes, de direitos fundamentais e assuntos federativos, o que explica a grande quantidade de conexões que estabelecem, mas também a diversidade dos campos temáticos com os quais entabulam relações.

Resta também claro que a leitura proposta não elimina outras formas de se visualizar a Constituição por outros eixos ou vetores axiológicos, tal como a defesa de direitos fundamentais, ou em torno de princípios, como o da dignidade da pessoa humana. Tratam-se com certeza elementos irradiadores que não necessariamente precisam ser verificados por meio das referências textuais entre os dispositivos do texto, tal como foi objeto da nossa análise. 
De qualquer modo, o conjunto de comunidades/subsistemas conectados na rede extraída do texto constitucional brasileiro demonstra a existência de eixos comunicativos, na acepção luhmanniana, com perfil consistentemente associado à determinação de limites e a processos para a atuação do Estado e seus agentes, representando a relevância das disposições liberais. Tais, disposições, como foi constatado na análise, estão vinculadas à concepção clássica que é a preocupação com a defesa de direitos individuais por meio da limitação do poder do Estado. Em outras palavras, significa, em última instância, que tais códigos emanados dos subsistemas detectados colaboram para diferenciação entre o Sistema do Direito e o Sistema da Política.

O eixo estruturante desses subsistemas se comunica e se relaciona com os demais temas que alcançaram a estatura constitucional, tais como as outras concepções de defesa da dignidade da pessoa humana e dos demais direitos fundamentais da ordem constitucional contemporânea, mostrando que a complexidade do sistema do Direito Constitucional brasileiro pode ser observada além de sua estrutura lógica sequencial.

\section{REFERÊNCIAS DAS FONTES CITADAS}

ALBERT, R.;iBARABÁSI, A. L, Statistical Mechanics of Complex Networks. In: Reviews of Modern Physics, 74, $\mathrm{n}^{\circ} 1,2002$, pp. 47-97.

ALVAREZ, Maria Esmeralda Ballestero. Organização, sistemas e métodos. São Paulo: McGraw-Hill, 1990.

BASHUR, João Paulo. Distanciamento e Crítica: limites e possibilidades da teoria de sistemas de Niklas Luhmann. Tese apresentada ao Programa de Pós-Graduação do Departamento de Ciência Política da Faculdade De Filosofia, Letras e Ciências Humanas da Universidade de São Paulo, 2009.

BACHUR, João Paulo. Inclusão e exclusão na teoria de sistemas sociais: aspectos críticos. BIB Revista Brasileira de Informação Bibliográfica em Ciências Sociais, v. 73, p. 55-83, 2012.

BARABÁSI, A.L. Graph theory. Network Science. 2012. Disponível em: <http://barabasilab.neu.edu/ networksciencebook/download/network_science_November_Ch2_2012.pdf>.Acesso em: 26 jul. 2020.

BARABÁSI, A. L. Network Science. Cambridge: Cambridge University Press, 2016.

BRASIL. Constituição Federal. Brasília: Senado Federal, 1988. Disponível em: <http://www.planalto.gov.br/ ccivil_03/constituicao/constituicao.htm >.Acesso em: 26 jul. 2020.

CANOTILHO, J. J. Gomes;MENDES, Gilmar F.; SARLET, Ingo W.; Streck, Lenio L. (Coords.). Comentários à Constituição do Brasil. São Paulo:Saraiva/Almedina, 2013.

JACOMY, M.; VENTURINI, T., HEYMANN, S.; BASTIAN, M. ForceAtlas2, a Continuous Graph Layout Algorithm for Handy Network Visualization Designed for the Gephi Software.In: Plos One, n 9, vol.6, 2014.

MATURANA, Humberto R.; VARELA, Francisco J. A árvore do conhecimento: as bases biológicas da compreensão humana. Trad. Humberto Mariotti e Lia Diskin. São Paulo: Palas Athena, 2001.

PATTY, J. W.; PENN, E. M. "Network Theory and Political Science".In: The Oxford Handbook of Political Networks. New York: Oxford University Press., 2017. 
RODRIGUES, Leo Peixoto; NEVES, Fabrício Monteiro. Niklas Luhmann: a sociedade como sistema. Porto Alegre: Edipucrs, 2012.

ROSSETTO, G.M.F, O Direito como sistema autopoiético na evolução jurídica da matriz teórica de Gunther Teubner. Revista Amicus Curiae, v. 7, 2011.

SOUZA, Queila Regina; QUANDT, Carlos Olavo, Metodologia de análise de redes sociais.In: O Tempo das Redes. São Paulo: Perspectiva, p. 31-63, 2008.

VERRIER, J. Lexmex: Code civil des Français. 2012. Disponível em: <www.lexmex.fr> . Acesso em: 26 jul. 2020.

LUHMANN, Niklas, Sociologia do direito. Rio de Janeiro, Edições Tempo Brasileiro,v. I e II, 1983.

LUHMANN, Niklas, The self-reproduction of law and its limits. In: TEUBNER, Gunther (ed.). Dilemmas of law in the Welfare State. Berlim/Nova York, Walter de Gruyter. 1986.

LUHMANN, Niklas. Sistemas sociais: esboço de uma teoria geral. São Paulo: Vozes, 2016.

TEUBNER, Gunther (ed.), Autopoietic law: a new approach to law and society. Berlim/Nova York, Walter de Gruyter, 1988.

TEUBNER, Gunther. O direito como sistema autopoiético. Lisboa, Fundação Calouste Gulbenkian, 1989.

Recebido em: 22/07/2020

Aprovado em: 16/12/2020

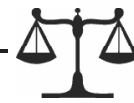

